\title{
CFAS: A WEIGHTLESS REFORM OF LEGAL AID?
}

\section{Richard Moorhead, Senior Research Fellow, Cardiff Law School}

Conditional Fee Arrangements (CFAs), an anglicised species of contingency fees, are a relatively recent addition to the civil justice system of England and Wales. They have opened up the world of legal services to new sources of funding, particularly insurance backed funding, and have also been the basis for the withdrawal of significant areas of personal injury work from the legal aid scheme. The government has claimed that, "conditional fees have already greatly extended access to justice. With conditional fees, people can take good cases, in the certain knowledge that [they] will not be left out of pocket if they lose (except by the amount of any insurance premium)."'1

CFAs have been with us since 1995 as a complement to the legal aid scheme for those clients who did not qualify for state funded help. ${ }^{2}$ Under a CFA, a solicitor usually acts on the basis that, if his client loses the case, the solicitor will be paid nothing. If the solicitor succeeds, her normal fees are paid with an "uplift" or "success fee". The success fee is based on a percentage of a solicitor's costs, rather than the U.S.-style contingency fee system which is based on the level of damages awarded to a client. An added complication in this system arises from our 'costs follow the event' rules. Although a CFA can protect a client against paying their own lawyers' costs, in the event that they lose their case, they would not be protected against payment of the other side's costs. To meet the potentially serious implications of this, the insurance market was encouraged to develop 'after the event' (AEI) insurance policies that could be taken out at the time the CFA was agreed and which would protect the client against such losses.

More recently, the Access to Justice Act 1999 (the AJA) has sought to extend and deepen the importance of CFAs in two main ways. Firstly, most personal injury cases were excluded from the scope of the new legal aid scheme. $^{3}$ This was on the assumption that the market for personal injury funding was ready to be supplied almost totally by CFAs and the insurance industry. It was also seen as a beachhead for the replacement of other parts of the civil legal aid scheme by CFAs, as the CFA market matured. In this sense, CFAs were no longer complementary to the legal aid scheme; in certain areas of law, they were to replace it. Secondly, would-be CFA clients were to be further encouraged to take CFA cases by reducing the costs of such agreements in two ways. Under the pre-AJA scheme, a successful claimant would pay the lawyer's success fees out of their damages and they

1 Lord Chancellor's Department (1999), Modernising Justice, hereafter, the White Paper, para 2.43.

2 Prior to Schedule 15 of the Access to Justice Act 1999, there was a statutory bar on taking the availability of CFAs into account in deciding whether to fund civil cases.

3 "Services consisting of the provision of help (beyond the provision of general information about the law and the legal system and the availability of legal services) in relation to- (a) allegations of negligently caused injury, death or damage to property, apart from allegations relating to clinical negligence," cannot be funded by the Legal Services Commission. Schedule 2, para. 1, AJA 1999. 
might have to pay the insurance premium, either out of damages or from the outset of the case. The 1999 Act made success fees and insurance premiums recoverable in large-part from the other side in the event that a CFA-client was successful in their claim.

This was seen as a crucial step towards making the market work. By adapting the normal costs-follow-the-event rules of the jurisdiction and translating these into a privately-funded version of the legal aid cost rules (because the claimant is typically protected from costs awards), it provides an interesting attempt to squeeze public provision of legal services into a private model approach. The replacement of legal aid was justified on the basis of the decline in legal aid eligibility at a time when the legal aid budget was increasingly seen as unaffordable. ${ }^{4}$ Implicit in this claim is the idea that CFAs are more affordable. CFAs were also seen as contributing to the efficiency and effectiveness of court procedures by encouraging lawyers to weed out weak cases and settle strong ones. ${ }^{5}$ This apparently elegant reinvention of legal aid as a privately funded, and managed, phenomenon is the subject of this article. It considers whether the claims made for CFAs are likely to match the reality of the claims made for our insurance-backed scheme. In particular, in saying that CFAs 'work' there are three important claims being made:

- CFAs extend access to justice;

- in a way that is as, or more affordable, than legal aid; and,

- which promotes efficient but effective justice.

It is these claims which are the principal concern of this article. A system which shifts public costs for litigation to a private market has the political virtue of apparent costlessness - to borrow a phrase from the economics literature - a weightless reform of the legal aid system. Has that been achieved?

\section{A Basic Description Of The Insurance Situation}

The market for CFAs in England and Wales is strongly dependent on the existence of "After the Event Insurance" (AEI). ${ }^{6}$ Clients who are advised to bring claims under CFAs can take out insurance cover against the risk of being ordered to pay their opponents' costs. Sometimes this cover extends to their own disbursements (experts' fees and so on). This generally leaves only their own solicitors' fees not covered, a risk which is borne by their solicitors under the CFAs. There are also after the event insurance policies, which include cover for the client's own lawyer costs, but these arrangements are typically not CFAs, and so fall outside the scope of this article.

${ }^{4}$ LCD (1998) Conditional Fees A Lord Chancellor's Department Consultation Paper (LCD, London March 1998).

5 Ibid.

6 After the Event Insurance is to be contrasted with insurance policies for legal expenses which precede the knowledge of a legal claim, for example, as part of holiday insurance or property insurance cover. 
The insurance market for CFAs is new, and immature. Two insurers started providing AEI in connection with CFAs in 1995, one in 1996, one in 1997, and five in 1998. ${ }^{7}$ The rest entered the market more recently. There are now reported to be over 60 insurers, claims management companies and similar organisations involved in AEI. ${ }^{8}$ The products vary in terms of the cover that they provide. There may be financial limits on the level of cover (so cover might extent only to $£ 10,000$ of the opponent's costs, or $£ 50,000$ or $£ 100,000$ for example), the types of cost which are covered (are disbursements covered, for example?) and the types of case that they cover. Most schemes concentrate on personal injury litigation, and deal with sub-species of such litigation, road traffic and employers' liability cases for example, under different premium scales. Premiums vary considerably, with some schemes having fixed rates for predictable cases (such as road traffic accidents), and other premiums being based on a variable percentage of the sum insured, up to $40 \%$ of the potential costs liability (often for medical negligence cases).

Callery v Gray (No 2) provides some indication of premium levels on one of the main schemes, and more generally:

“. . . under the Law Society approved Accident Line Protect Scheme (sold by Abbey Legal Protection Limited) the current premiums (including IPT) for different classes of CFI are as follows: road accident claims (RTA), $£ 315$ fast track, and $£ 693$ multi- track; occupational disease $£ 892.50$ fast track and $£ 3,045$ multi track; other claims $£ 682.50$, fast track and $£ 2,520$ multi track.

. . A search of www.thejudge.co.uk conducted by the Association of Personal Injury Lawyers (APIL) shows the range of RTACFI to be $£ 210$ to $£ 1,050$ for the fast track and $£ 210$ to $£ 1,837$ for the multi-track. These figures, which are inclusive of IPT, are for policies which have differing limits of indemnity. The $£ 210$ premiums are for AMICUS policies which have a limit of indemnity of $£ 100,000$. The $£ 1,050$ premium is for a Wren policy and the $£ 1,837$ is for a Temple policy (which is described further in paragraph 65, below); both of these policies have a limit of indemnity of $£ 50,000 . " 9$

There are two main types of AEI policy in use with CFAs. Policies are either:

- $\quad$ individually underwritten, or

- $\quad$ issued under delegated authority.

Under delegated authority schemes the insurers assess a solicitor's firm and, if the firm becomes a member of the insurer's scheme, whenever the firm

7 These descriptions of insurance providers are largely taken from (1999) 1 Litigation Funding, pp 12-13. See also, P. O’Mahoney et al, (1999) Conditional Fees: Law and Practice (Sweet and Maxwell London).

8 See the report of Master O'Hare appended to Callery v Gray (No.2) [2001] 1 W.L.R. 2142, C.A. para 9.

9 Master O'Hare's report to the Court of Appeal, paras 14 and 24, in Callery v Gray (No 2) [2001] 1 W.L.R. 2142, C.A. 
takes a case under a CFA, cover is automatic. Firms are usually required to sign exclusivity agreements whereby they are not permitted to send cases to other insurers. They must insure all their CFA, speculative and noncontentious contingency fee cases with the insurer. This is designed to prevent adverse selection, whereby the firm would not bother incurring the expense of insurance on its better cases on the assumption that such expenditure was unnecessary. This would mean that the insurer was asked to insure only the riskier cases, leading to higher premiums and more adverse selection.

Individually underwritten policies are issued on a case by case basis. Firms make an application on their client's behalf and sometimes pay an application fee themselves. The insurance companies then assess the merits of the application (often in-house) before deciding whether to grant cover and on what terms.

Even with insurance, CFAs bring with them a number of potential costs, some of which may need to be borne up-front by the client, or by the solicitor's firm.

- The cost of the premium (although this may be payable at the end of the case and only if a case is successful, under 'magic bullet' schemes);

- An application fee (possibly);

- Barristers' fees and solicitors' disbursements incurred in the course of the case and before the case is completed (although barristers may themselves be instructed on a CFA);

- The cost of borrowing. A firm conducting CFA work will have a number of costs which it bears whilst it is running a CFA case. If it pays the premium and disbursements for the client, for example, and recovers these when the case is completed, it will nevertheless have borne a cost in terms of carrying that cost for the life of the case. Similarly, there is a cost in terms of the work which it incurs on a case (the work in progress), but which is not billed until the end of the case. These costs are collectively known as the cost of borrowing.

These costs have the potential to discourage either clients or firms from taking on CFA work. As already noted, the insurance schemes have begun to develop solutions to some of these problems, such as allowing the insurance premium to be paid at the end of a case, and only on cases that are successful. Given that reasonable insurance premiums are recoverable from the losing party (subject to limitations and exceptions), ${ }^{10}$ the insurance aspects of CFA schemes have the potential to operate at little or no cost to claimants. Some costs remain to be borne by firms, notably the cost of borrowing and the risk of not getting paid themselves should the case not succeed.

It is these costs that a solicitor can seek to recover in the 'uplift' on costs charged when a case is successful. The current limit on uplifts is $100 \%$ of basic costs. Therefore, in theory, a lawyer can charge double their normal costs for successful cases. The basis for allowing a $100 \%$ uplift was that it

10 Callery v Gray (No. 1) [2001] 3 All E.R. 833, C.A. 
would allow lawyers to take on cases approaching a 50:50 chance of success on a basis that reflected their risk. As has already been noted however, the uplift can reflect both this risk and the cost of borrowing. These must be specified separately. Only the uplift attributable to risk is recoverable from the losing party. Any uplift for the cost of borrowing is payable by the client. Thus, recoverability is not total. Clients may well end up paying 'cost of borrowing' uplifts were their cases are successful particularly if courts control the level of success fees recoverable from losing parties as they have begun to do. Thus, the Court of Appeal recently laid down a guideline for straightforward personal injury road traffic claims that a 'risk' uplift of $20 \%$ would be likely to be reasonable. ${ }^{11}$

Having outlined the way that CFAs work and their relationship to the insurance market, it is now possible to consider the more fundamental questions posed.

\section{Do CFAs Extend Access To Justice?}

Had the government not decided to replace aspects of the legal aid scheme with CFAs, this question would not need to be asked. A CFA scheme which is used by some clients and which complements a legal aid scheme must increase access to justice whether or not CFAs have other faults. But given that many thousands of people who would have qualified for legal aid now have to attempt to pursue cases by CFAs, there is an interesting questionmark over the efficacy of CFAs as an extender of access to justice. The question can be answered in a number of ways.

Firstly, are those who would have qualified for legal aid under the old scheme equally (or more) likely to be able to get access to CFAs? Some insurance schemes claim to allow cases if they have prospects of success marginally higher than $50 \%$. In theory, this would be similar to the old legal aid scheme. However other data on the actual approach of firms and insurers suggests the reality may be somewhat different from the theory. For example, the prospects of success expected of firms operating conditional fee agreements under delegated authority schemes need to be considerably higher than the prospects of success under the legal aid scheme. Some firms quote success rates as high as $98 \%$ and insurers understandably expect high success rates (reported to be 95\%). The Legal Services Commission's general funding code for non-personal injury cases shows that prospects of success can be as low as 50-60\% if the damages to be won are sufficiently higher than the costs that would be incurred. Pleasance has shown that even road traffic personal injury cases under the legal aid scheme had a success rate of over $80 \% .^{12}$ Other types of personal injury litigation had lower levels of success. It seems likely that it will be more difficult to get funding for a personal injury claim under a CFA (where de facto the chances of success would appear to need to be high enough for firms to get overall success rates of $95 \%$ and above) than it would be for the case to be funded under the old legal aid scheme or under the LSC's legal aid funding code (if personal injury were not excluded). There are other indications of the way in which

11 Ibid.

12 Pleasance (1998) Personal Injury Litigation in Practice (LABRU, London) p 10. 
individual cases are less likely to be funded now. For example, insurers are reportedly reluctant to fund cases where a defence has been filed. ${ }^{13}$

The evidence points to fewer legally aidable cases getting CFA funding, but it also points to specific types of case being more difficult to fund. The government's own commissioned research predicted a degree of specialisation on more severe cases would be more profitable than high volume, low-margin work and that this profitability might be improved by applying more stringent merits tests to such claims. ${ }^{14}$ In other words, it predicted access would narrow to higher margin, bigger cases. It similarly pointed out that CFA funded, "personal injury litigation can make a significant positive contribution to the overall profitability of a firm of solicitors. This is true on the assumption that clients will be unable to meet over half $(60 \%)$ of costs up front, and it remains true, albeit at slightly lower levels of profitability, even if clients can meet none of the costs up front.".15 Again, this means that firms would be more inclined to deal with clients who can pay the costs of borrowing up front. Access might be narrowed most acutely for 'legally aidable' clients. Shapland et al conducted a study of a small number of actual law firms conducting personal injury work and sought to project the impact of the legal aid reforms on the basis of financial information and information on case-handling gained through interview and a review of the firms' accounts. ${ }^{16}$ For current purposes the main findings were: specific problems with CFAs for cases where there were significant questions of liability and serious injury where there was likely to be considerable investigative cost and effort, emphasising in particular industrial disease cases and complex accidents at work. ${ }^{17}$ Again, this suggested that for these types of case, access would narrow.

These arguments can be mitigated in two main ways. One way is to suggest that the tightening up of the merits test is desirable in any event, as it means that only 'good' cases are taken forward. This point is dealt with more fully below. A second argument is more pragmatic. This argument would accept that CFAs have excluded some cases which would have been funded previously in legal aid, but argue that more people have benefited than have lost out from the reforms. Thus, it might be said that the number of people who would not have qualified for legal aid, who nonetheless could not afford a lawyer, but who would now proceed under a CFA, outweighs the number of legally aidable clients who could not get CFA funding.

Ultimately, this comes down to numbers. Data on the impact of CFAs on the number of people helped by CFAs, comparing the pre and post legal aid reform periods, is poor. We simply cannot say if the increase in take up of CFAs has overtaken the reduction in legal aid funding. It is clear that big providers of CFA and CFA-like services have developed systems of mass advertising and delivery ${ }^{18}$ and these have led to higher levels of claiming

13 Master O'Hares Report in Callery v Gray (No 2) supra n 9, para 26

14 KPMG (1998), Conditional Fees Business Case (LCD, London).

15 Ibid $\mathrm{p} 2$

16 Shapland et al (1998), Affording Civil Litigation (Law Society, London).

17 Ibid at ix.

18 The Accident Group (a network for solicitors firms doing CFA work) is estimated to account for $14 \%$ of the market for personal injury claims and appears to be the 
than previously, and so higher levels of access to justice. CFAs may well have helped more people than they hindered. The difficult question which remains unanswered is whether it was necessary to abolish legal aid for personal injury work to achieve this gain. Unless the CFA market was so weak that it needed its main rival, the legal aid fund, to be abolished, then it could be persuasively argued that a legal aid fund operating alongside a CFA scheme would have achieved higher levels of access to justice than the current scheme. In other words, the benefits of CFAs to 'middle income' clients could have been achieved without the abolition of legal aid.

A final way of dealing with the diminution of access argument is to point out that any diminution in the overall levels of access to lawyers for personal injury claimants has been compensated for by an increase in access in other areas of the law. The money saved from the legal aid scheme by excluding personal injury could be redistributed to other areas of legal need. The government estimated that this money was in the region of $£ 32$ million. ${ }^{19}$ Putting aside whether this money was in fact introduced back into the legal aid budget, this is an apparently small part of the overall legal aid budget (between 2 and 3\%); though a large proportion of the money spent on legal help in social welfare law areas. Whether the access benefits of redistributing that sum to (say) immigration advice would be worth any loss in personal injury law access is very hard to say. Evaluating which would have a greater benefit in social and/or economic terms is almost impossible, particularly on current data.

\section{CFAs Are As, Or More Affordable, Than Legal Aid}

Because CFAs do not have to cost the client anything if the lawyer waives certain charges and the insurance arrangements are structured in a certain way, then from a claimant perspective, CFAs look like a very good deal. Similarly, the public purse, or at least the legal aid pocket of it, is not called upon for most personal injury cases. So, from the LCD and Treasury perspective, CFAs also look like a very good deal. But that leaves open the question of whether CFAs, and the costs associated with them, represent better value for money than the old legal aid scheme. Ultimately, any additional costs of claims are met out of increased insurance premiums.

Is it possible to understand whether the CFA scheme is more expensive than the old legal aid scheme would be? Arguably it is, although any such estimate is based on quite crude data about the costs of legal aid cases and even poorer information about CFA cases. In 1996/97 the Legal Aid Board (as it then was) had about 81,000 legal aid certificates; the total cost of these cases was $£ 273$ million, of which the net cost to the fund was $£ 48$ million. ${ }^{20}$ The cost of funding these cases was $£ 593$ per case to the Legal Aid Board

largest provider of insurance backed CFAs. It currently estimates getting between 9,000 and 12,500 claims a month.

19 The costs savings to the Legal Aid Fund of removing all personal injury cases from the legal aid scheme were originally estimated as being in the region of $£ 37$ million. Parliamentary answer, Geoff Hoon MP, Minister of State LCD $\left(2^{\text {nd }}\right.$ February 1999). See (1999) 1 Litigation Funding 12.

20 P. Pleasance (1998), supra n 12, pp 9-10. 
and $£ 2,778$ per case to the insurance companies (excluding any damages paid).

If one looks at the costs of funding the same cases on CFAs, it is necessary to make a number of assumptions. Let us assume that the average premium paid per case is $£ 350$ (based on the figures given in Callery v Gray for the cheaper Accident Line Protect policy for RTA fast track cases). Let us also assume that the premium is only paid in $90 \%$ of cases (as a magic bullet type scheme). On these assumptions, which may be generous in the CFA scheme's favour, the premium costs are considerably lower than the net costs to the Legal Aid Board (about $£ 26$ million compared with $£ 48$ million, even before the Board's administration costs are added in). If we assume also that the same cases would raise the same amount of ordinary profit costs (£273 less $£ 48$ million), then we need also to add a success fee for such cases. If we assume the success fee for straightforward RTA cases suggested in Callery v Gray then claimants would usually claim (upwards of) $20 \%$ of their profit costs. On these calculations, the CFA scheme would cost $£ 296$ million and the legal aid scheme $£ 273$ million (plus the Legal Aid Board’s administration costs), a difference of $£ 23$ million (or £278 per case).

However, a significant proportion of the insurance premiums paid out by insurance companies when they lose cases will be repaid to these insurance companies when they recover their costs against unsuccessful claimants' AEI insurance policies. If we were to assume that $75 \%$ of the insurance premiums were farmed back to insurers in costs payments then the difference between the CFA and legal aid scheme costs reduces significantly to about $£ 6$ million. That reduction would increase further were legal aid administration costs factored into the equation.

Were all these assumptions to hold true, then CFAs would seem to be only marginally more expensive than the legal aid scheme. It is probably fair to assume however, that such assumptions will not hold. Insurance premiums are often higher and the $20 \%$ uplift figure is the figure supported by the courts for the simplest cases. Higher uplifts are likely to add significantly to the costs of CFAs in other cases. Each 10\% increase in the average uplift is likely to make the funding of a cohort of CFA cases of comparable size to the old legal aid scheme about $£ 22$ million more expensive than the equivalent system of legal aid; an increase in costs of about $£ 275$ per case. 


\begin{tabular}{|c|c|c|c|c|}
\hline \multirow[b]{2}{*}{$\begin{array}{l}81,000 \\
\text { Cases }\end{array}$} & \multicolumn{2}{|c|}{ Legal Aid scheme } & \multicolumn{2}{|l|}{ CFA equivalent } \\
\hline & 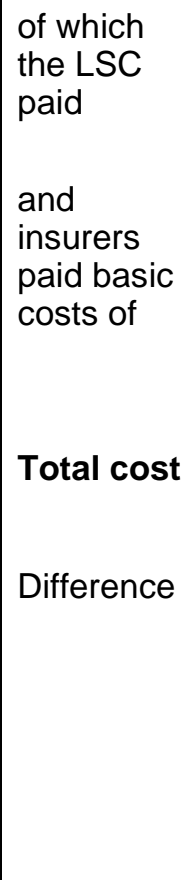 & $\begin{array}{l}£ 48,000,000 \\
£ 225,000,000 \\
£ 273,000,000\end{array}$ & $\begin{array}{l}\text { Insurance } \\
\text { premiums on } \\
90 \% \text { of all } \\
\text { cases' } £ 350 \\
\text { And insurers } \\
\text { pay same basic } \\
\text { costs } \\
\text { Plus uplift (@ } \\
20 \% \text { ) } \\
\\
\\
\text { Less costs } \\
\text { recovered from } \\
\text { AEI (75\% of £25 } \\
\text { million) } \\
\text { Extra cost of } \\
\text { CFA equivalent }\end{array}$ & $\begin{array}{l}£ 25,515,000 \\
£ 225,000,000 \\
£ 45,000,000 \\
£ 295,515,000 \\
£ 22,515,000 \\
\\
\frac{£ 18,750,000}{£ 6,378,750}\end{array}$ \\
\hline
\end{tabular}

In cost terms, the result of CFA reforms seems to be to shift the existing cost of funding personal injury litigation away from the state towards insurers and their policy holders. In public policy terms this has the benefit of making the 'polluter' (here largely motorists) pay more of the cost of their tort (through increased insurance premiums). An interesting side-effect of this reform is the increase in cost, over and above the original costs of the legal aid scheme, which have been caused by AEI insurance premiums and CFA uplifts. CFAs are more expensive, not cheaper.

\section{CFAs Promote Efficient But Effective Justice?}

A key aspect of CFAs is the discipline that commercial forces may exert on personal injury litigation. This discipline takes a number of forms but two main ones are of interest. The first is the claim that only 'good' cases will be taken under CFAs. The second is that CFAs will help promote sensible settlement.

\section{The Moral Hazard Problem - Ensuring Only 'Good' Cases Are Taken}

A criticism of legal aid funded litigation is that it encourages the taking of cases with poor prospects of success, because neither the claimant nor their lawyer bears sufficient risk of the case losing, creating a 'moral hazard'. Because CFAs require lawyers (and sometimes clients) to bear more risk, 
this moral hazard is reduced. This argument has allowed government to claim that only 'good' cases can proceed under CFAs.

The claim that only good claims will be taken under CFAs obviously defines 'good' in a peculiarly economic sense. The theory is that CFAs discipline solicitors to take cases where the prospects of success are high, because if they do not, then they will lose too much of their costs to be successful. There are two main problems with this theory. One is that the definition of what constitutes sufficiently high prospects of success may be particularly high. Insurers are reported to expect high success rates (about $95 \%$ is the figure usually quoted) from solicitors on their delegated insurer schemes, and are prepared to strike firms off their solicitor panels if the lower limit is not achieved. Not surprisingly, because their survival in the insurance market and profitability depends upon it, insurers put their own commercial interests first in their approach to risk assessment. Thus, the definition of a 'good' case may actually mean 'a very good case indeed'. Compare a 95\% success rates with the $80 \%$ achieved under legal aid on road traffic cases for example, ${ }^{21}$ and you get a sense of the number of cases which would be strong but not strong enough to get a CFA.

A second problem is that a risk-based/economic based theory of litigation relies on firms behaving in an economically rational way. It also tends to rely on a notion of a reasonably sized firm able to bear a certain amount of risk with equanimity. There is however evidence that firms may be more risk-averse than they should be if they were totally rational. ${ }^{22}$ Shapland's study emphasises that firms' individual approach to billing and their own financial profiles could have a significant effect on the viability of conditional fee arrangements for those firms. ${ }^{23}$ Defendant behaviour and local conditions (such as the cost of expert reports) could significantly affect the profitability of CFA work. ${ }^{24}$ Thus the notion of risk, which determines when a case is 'good' might be highly specific to the firm assessing the risk rather than the prospects of a case being taken on. The cool discipline of economics is in fact a much more arbitrary affair, particularly if one remembers that clients do not appear to shop around for CFAs. ${ }^{25}$ Another report provides some insight into the handling of CFAs by solicitors' firms. ${ }^{26}$ It shows considerable variability in the existence and quality of risk assessment in firms. ${ }^{27}$ The quality and variability of risk assessments (in so far as made properly or at all) raise concerns about the competence of solicitor firms to assess cases for CFA funding and thus to act in their clients' best interests. The notion of a 'good' case in an adversarial justice system is an inevitably controversial phenomenon. Good could mean arguable, winnable, likely to win or a near certainty. It could also mean

21 Ibid at $\mathrm{p} 10$

22 See, for example S. Yarrow, Just Rewards: the outcome of conditional fee cases (Nuffield, London, 2000).

23 Shapland et al supra $\mathrm{n} 15$ at ix.

24 Ibid $\mathrm{p} 84$.

25 S. Yarrow and P. Abrams, Nothing to lose? Clients' experiences of using condtional fees (Nuffield, London, 1999).

26 BDO Stoy Hayward, Conditional Fee Arrangements, A survey compiled by BDO Stoy Hayward (February 1999).

27 Ibid p 4. 
something quite different. A 'good' case could be one where the interests involved are so important that they need to be heard. CFAs work purely on the economic model - do the risks merit the rewards? - not on any broader notion of justice. Even the economic criterion is one which may not fit with any certainty. What looks like one firm's good case, looks like another's bad case.

\section{The Lack Of Settlement Problem}

The commercial discipline of CFAs may also have a beneficial effect on the conduct of cases. A criticism of the legal aid scheme was that the legally aided lawyer, with a guaranteed cheque from the Legal Services' Commission, and a client who had nothing to lose, was under no incentive to settle. This was a simplification. Legal aid lawyers would usually get paid higher hourly rates if they settled than if they relied on the legal aid fund, and clients had the last settlement offer to lose if they pushed things too far. Nevertheless, CFA lawyers, with a stronger direct interest in achieving some settlement, are under a stronger economic incentive to settle the case. The 'commercial discipline' argument suggests that this leads to appropriate levels of settlement.

This is perhaps the most difficult aspect of the CFA reforms to assess. It assumes that because both the lawyer and client are under some pressure to settle, their interests are aligned and the very fact of settlement is appropriate. This may not be the case. It depends on the incentives and risks of lawyers and clients being perfectly aligned. There are, however, some obvious differences. The client is typically a one-shotter interested in one transaction. The lawyer spreads risk and reward over an entire caseload. Furthermore a client's interest is in damages. Lawyers do not have a direct interest in the level of damages the client receives, because the CFA success fee is set by reference to the lawyers' basic costs not the damages. This has some benefits. The risk that lawyers will take big damages cases, do minimal work, but nonetheless claim a large success fee from the damages is removed. Similarly, the lawyer has incentives to do more work where this is going to lead to an improved offer for the client, as their extra costs will be recoverable. But there is some evidence that lawyer and client incentives may sometimes get out of kilter. Lawyers in personal injury practice appear to be beginning to recognise that they need to have a steady stream of quick and easy cases to keep a practice running. ${ }^{28}$ Thus a lawyer may be more interested in cashflow than their client and thus tempted to try and settle cases quickly. Certainly a settlement means they get paid something, whereas pushing on might mean getting paid nothing. Another factor is the context in which the risks of settlement are assessed. It is often assumed that a firm assesses the risks of rejecting a settlement offer in terms of the overall interests of the firm. It can spread the risk of losing more widely, take the risks of pushing on, incur more costs and make more money in the long run. The difficulty with this theory is that bigger firms often operate on the basis of individual fee earner targets. Thus individual fee earners are kept under pressure to keep fees coming in. Promotion, or even job security, may

28 T. Goriely, P. Abrams and R. Moorhead, More Civil Justice? (Law Society, London, 2002). 
depend upon it. Fee earners treated in this way may be more inclined to settle to keep their bills delivered figures high. A final factor of some importance is the insurers' position. Whilst lawyer and client have a degree of similarity of interest which may mitigate the desire to under-settle, the insurance companies do not. They do not get paid more if the case is pushed farther, nor do they have any interest in the level of damages recouped. All they want is for the case to settle, so that they do not have to meet a large bill for the other side's costs should the case lose.

These arguments problematise the commercial discipline thesis, but they do not totally destroy it. They point to the potential for the lawyer's interest to conflict with the client's interests. Certain aspects of the CFA scheme, notably the role of the insurer, are more obviously antithetical to the client's interests. The lawyer-client conflict is more subtle. Sometimes the financial incentives on lawyers will boost client damages, sometimes they will shrink damages. In others, the incentives may be neutral. Insurers have the potential to exert a chilling effect, hence a concern that any such system will operate to a client's detriment when compared with other methods of funding. Nevertheless, the main point of this critique is that the apparent clarity of financial incentives is in reality much more uncertain.

\section{SUMMARY AND CONCLUSIONS}

This article has concentrated on critiquing the three fundamental claims made for CFAs. In terms of whether CFAs have extended access to justice, it appears likely that in straightforward personal injury cases for middleincome clients who were previously unable to claim legal aid, CFAs will have extended access to justice quite significantly. For clients who would have qualified for legal aid, however, the coupling of CFAs with the removal of legal aid for most personally injury actions has probably reduced access to justice. Although it is possible that the money saved on personal injury actions has been redistributed to other areas of the legal aid budget, thus creating a net gain in access to justice, the likely result of the reforms is that for formerly legally aidable clients, legal representation is now available for fewer cases than previously. Conversely, although it seems unlikely, it is at least arguable that it was necessary to remove legal aid to stimulate the legal expenses insurance market sufficiently to provide the levels of access which CFAs currently afford to the formerly legally aidable and middle-income clients.

The second argument was that CFAs are more affordable than legal aid. Essentially, however, what the CFA reforms have done is shift the public expenditure cost of personal injury litigation on to insurers and insurance policy holders. Only if insurance premiums and success fees are kept very low will the cost of CFA funded litigation be similar to the cost of legal aid funded personal injury litigation. The likelihood is that CFA funded litigation will be considerably more expensive than legal aid funded litigation. A significant advantage to the government, of course, is that these costs are borne privately, rather than through public expenditure. Motorists and other insurance policy holders will pay more, taxpayers will pay less. Whilst this has the advantage of shifting more of the cost-burden of litigation onto the activities of tortfeasors, the overall burden of personal injury litigation costs will probably be higher. 
The third argument is that CFAs promote more efficient but effective justice because they reduce the moral hazard of litigation funding by ensuring only "good cases" are taken forward and they encourage a commercial discipline which makes it more likely that cases will settle expeditiously. This, however, means that the notion of a "good case" is a narrowly economic one. "Good" means cases with very strong prospects of success as judged by solicitors' firms and insurers. Defendant behaviour, the cost of running cases, the profitability of individual firms and the risk and profit profiles of insurance companies are all likely to determine what constitutes a "good case". Broader notions of justice and public interest are thus demoted behind the bottom line of firms and insurance companies. Similarly, the argument that commercial discipline will lead to more appropriate settlement is problematic. The economic incentives of lawyers, clients and insurance companies would need to be in near perfect alignment were commercial discipline itself to lead to appropriate levels of settlement. There is a risk, in particular, that clients funded under CFA agreements will get lower levels of settlements than they would have done had they been clients funded under other types of fee arrangements.

There are other criticisms that can be made of CFA agreements. Their complexity baffles clients (and even lawyers). ${ }^{29}$ Partly, this is caused by the continuing existence of the indemnity principle. Clients may be locked into agreements which define a "win" in a way which would not accord with common sense notions of what a win means. They may also find themselves locked into agreements which they cannot get out of, ${ }^{30}$ or facing bills for the non-recoverable part of CFA uplifts. ${ }^{31}$ Recoverability means that usually neither the claimant lawyer nor the client bear the cost of insurance policies. This in turn probably means there is effectively no competitive market for insurance premiums. Similarly, because the risk part of the conditional fee uplift is not borne by the client, there is no market control of the uplift. This means that increases in the cost of CFAs are likely to be policed solely by the courts. It is questionable whether the courts are, or feel, able to do this task adequately. ${ }^{32}$ There are other problems, such as the relationship between CFA after the event insurance and other forms of legal expenses insurance which may be cheaper. ${ }^{33}$ Similarly, question marks have been raised over whether AEI premiums can be deferred under so called magic bullet schemes. ${ }^{34}$

It is to be hoped and expected that, as the system matures, some of the difficulties of CFAs and the insurance market will reduce. It will be very difficult, however, to gain appropriate control over uplifts and insurance premiums without restricting further the willingness of firms and insurance companies to take meretricious cases. A system which fragments and commercialises risk also hides from public gaze the necessary information to

29 See Yarrow and Abrams supra $\mathrm{n} 24$.

30 See The Society of Advanced Legal Studies, The Ethics of Conditional Fee Arrangements (SALS, London, 2001) and Yarrow and Abrams ibid.

31 Lawyers can recover an uplift from their clients if it relates to the cost of borrowing, rather than the risk on their case.

32 See Callery v Gray (Nos 1 \& 2) supra $\mathrm{n} 8$ and $\mathrm{n} 10$.

33 Sarwar v Alam [2002] 1 WLR 125.

34 Tilby v Perfect Pizza (28 $8^{\text {th }}$ February 2002, unreported). 
166 Northern Ireland Legal Quarterly [Vol. 53, No. 2]

understand how the scheme is operating and whether it operates in the public interest. CFAs are not a disastrous reform, they continue to provide a degree of access to justice for large numbers of people, but they are not a weightless alternative to the legal aid scheme. 